\title{
First observation of tropospheric nitrogen dioxide from the Environmental Trace Gases Monitoring Instrument onboard the GaoFen-5 satellite
}

Chengxin Zhang $\mathbb{1}^{1}$, Cheng Liu ${ }^{2,3,4,5}$, Ka Lok Chan ${ }^{6}$, Qihou Hư ${ }^{3}$, Haoran Liu', Bo Li', Chengzhi Xing ${ }^{1}$, Wei Tan ${ }^{3}$, Haijin Zhou $^{3}$, Fuqi $\mathrm{Si}^{3}$ and Jianguo $\mathrm{Liu}^{3,4}$

\begin{abstract}
The Environmental Trace Gases Monitoring Instrument (EMI) is the first Chinese satellite-borne UV-Vis spectrometer aiming to measure the distribution of atmospheric trace gases on a global scale. The EMI instrument onboard the GaoFen-5 satellite was launched on 9 May 2018. In this paper, we present the tropospheric nitrogen dioxide $\left(\mathrm{NO}_{2}\right)$ vertical column density (VCD) retrieval algorithm dedicated to EMI measurement. We report the first successful retrieval of tropospheric $\mathrm{NO}_{2} \mathrm{VCD}$ from the EMI instrument. Our retrieval improved the original EMI $\mathrm{NO}_{2}$ prototype algorithm by modifying the settings of the spectral fit and air mass factor calculations to account for the on-orbit instrumental performance changes. The retrieved $\mathrm{EMI} \mathrm{NO}_{2} \mathrm{VCDs}$ generally show good spatiotemporal agreement with the satellite-borne Ozone Monitoring Instrument and TROPOspheric Monitoring Instrument (correlation coefficient $R$ of $\sim 0.9$, bias $<50 \%$ ). A comparison with ground-based MAX-DOAS (Multi-Axis Differential Optical Absorption Spectroscopy) observations also shows good correlation with an $R$ of 0.82 . The results indicate that the $\mathrm{EMI} \mathrm{NO}_{2}$ retrieval algorithm derives reliable and precise results, and this algorithm can feasibly produce stable operational products that can contribute to global air pollution monitoring.
\end{abstract}

\section{Introduction}

The Environmental Trace Gases Monitoring Instrument $(E M I)^{1}$ is the first Chinese satellite-borne spectrometer with the aim to measure atmospheric pollutants from space. The EMI payload onboard the GaoFen-5 satellite was successfully launched on 9 May 2018. The GaoFen-5 satellite has a polar orbit at an altitude of $706 \mathrm{~km}$. The Chinese EMI instrument is expected to contribute to the understanding of global air quality and atmospheric chemistry, similar to predecessor European and American satellite missions, e.g., the Ozone Monitoring Instrument

Correspondence: Cheng Liu (chliu81@ustc.edu.cn) or Ka Lok Chan (ka.chan@dlr.de)

${ }^{1}$ School of Earth and Space Sciences, University of Science and Technology of China, Hefei 230026, China

${ }^{2}$ Department of Precision Machinery and Precision Instrumentation, University of Science and Technology of China, Hefei 230026, China

Full list of author information is available at the end of the article

These authors contributed equally: Chengxin Zhang, Cheng Liu
$(\mathrm{OMI})^{2}$ and TROPOspheric Monitoring Instrument $(\mathrm{TROPOMI})^{3}$. EMI has instrumental characteristics that are similar to OMI and TROPOMI, e.g., the local overpass time at $\sim 13: 30$, spectral coverage, push-broom imaging technique, and daily global coverage. Both EMI and TROPOMI (launched in 2017) are new-generation satellite-borne air pollutant sensors compared to the OMI that was launched in 2004. TROPOMI follows the heritage of OMI in both instrument design and trace gas retrievals, but with higher spatial resolution and signal-to-noise ratio. A prototype EMI nitrogen dioxide $\left(\mathrm{NO}_{2}\right)$ retrieval algorithm was developed before launch based on the OMI $\mathrm{NO}_{2}$ retrieval. However, optimization of the $\mathrm{NO}_{2}$ retrieval algorithm was necessary to adapt the unexpected issues of EMI after launch, especially spectral calibration.

Nitrogen oxides $\left(\mathrm{NO}_{\mathrm{x}}\right)$, defined as the sum of nitrogen oxide and $\mathrm{NO}_{2}$, are the major pollutants contributing to ozone and secondary aerosol formation in the

\section{(c) The Author(s) 2020}

(c) (i) Open Access This article is licensed under a Creative Commons Attribution 4.0 International License, which permits use, sharing, adaptation, distribution and reproduction cc) in any medium or format, as long as you give appropriate credit to the original author(s) and the source, provide a link to the Creative Commons license, and indicate if changes were made. The images or other third party material in this article are included in the article's Creative Commons license, unless indicated otherwise in a credit line to the material. If material is not included in the article's Creative Commons license and your intended use is not permitted by statutory regulation or exceeds the permitted use, you will need to obtain permission directly from the copyright holder. To view a copy of this license, visit http://creativecommons.org/licenses/by/4.0/. 
troposphere through photochemical reactions ${ }^{4}$. Sources of $\mathrm{NO}_{\mathrm{x}}$ include fossil fuel combustion, vehicle emissions, biomass burning, and lightning ${ }^{5}$. Due to rapid industrialization and urbanization in the past few decades, China has become one of the largest $\mathrm{NO}_{\mathrm{x}}$ emitters in the world $^{6}$. As a result, China is experiencing a series of severe air pollution problems ${ }^{7,8}$. In addition to measuring $\mathrm{NO}_{2}$ distribution directly from space, applications of satellite remote sensing may include estimations of pollutant emissions ${ }^{9}$, air quality trend detection ${ }^{10}$, model validation, and assimilation of satellite data ${ }^{11}$.

Figure 1a illustrates the optical design of the EMI satellite instrument. The EMI instrument covers the ultraviolet (UV) and visible (Vis) spectral ranges from 240 to $710 \mathrm{~nm}$ with a spectral resolution of $0.3-0.5 \mathrm{~nm}$. Light received by the telescope is depolarized by a scrambler and subsequently split into four spectral channels, the UV1 (240-315 nm), UV2 (311-403 nm), VIS1 (401-550 nm), and VIS2 $(545-710 \mathrm{~nm})$ channels. Each spectrometer is equipped with a two-dimensional chargecoupled device (CCD) detector, with one dimension used for spectral coverage and the other dimension used for spatial coverage. The EMI instrument scans in the nadir direction toward the earth's surface with an opening angle of $114^{\circ}$ corresponding to a swath width of $2600 \mathrm{~km}$, enabling daily global coverage with a nadir resolution of $12 \times 13 \mathrm{~km}^{2}$ and a local overpass time of 13:30 (Fig. 1b). The direct sun solar irradiance spectrum, typically used as a reference spectrum in the spectral analysis of the nadir radiance measurement, is introduced to the EMI telescope once a day using the quartz volume diffuser ${ }^{12}$. By using the unique absorption features of different trace gases in the UV-Vis range, the abundances of atmospheric pollutants can be retrieved from the difference between atmospheric and solar spectra.
In this paper, we present a new tropospheric $\mathrm{NO}_{2}$ vertical column density (VCD, i.e., the vertical integral of $\mathrm{NO}_{2}$ concentration from the earth's surface to the top of the atmosphere) retrieval algorithm dedicated to the EMI instrument. Details of the spectral retrieval, stratospheric-tropospheric separation of the $\mathrm{NO}_{2}$ column and slant to vertical column conversion are presented. The first EMI retrieval of tropospheric $\mathrm{NO}_{2}$ columns is compared to datasets from modern state-of-the-art European and American satellite sensors.

\section{Results}

\section{$\mathrm{NO}_{2}$ retrieval overview}

The retrieval of tropospheric $\mathrm{NO}_{2}$ VCDs from satellite UV-Vis observations typically follows a state-of-the-art three-step approach. First, the total $\mathrm{NO}_{2}$ slant column density (SCD) are retrieved from nadir radiance spectra normalized by the solar irradiance, using the differential optical absorption spectroscopy (DOAS) technique ${ }^{13}$. Subsequently, the stratospheric $\mathrm{NO}_{2}$ columns are separated from the total $\mathrm{NO}_{2}$ SCDs by assuming longitudinal homogeneity of stratospheric $\mathrm{NO}_{2}$, while neglecting the minor contribution of tropospheric $\mathrm{NO}_{2}$ (usually on the order of $10^{14}$ molecules $\mathrm{cm}^{-2}$ ) over remote clean regions ${ }^{14,15}$. Last, tropospheric $\mathrm{NO}_{2}$ SCDs are converted to VCDs using air mass factors $(\mathrm{AMFs})^{16}$. The AMF is defined as the ratio between SCD and VCD. It is a measure of the effective optical path length from the top of the atmosphere to the earth's surface and reflected to the satellite through the atmosphere:

$$
M=\frac{S}{V}
$$

where $M$ is the AMF, $S$ denotes the SCD, and $V$ represents the VCD. The AMF can be calculated with a radiative

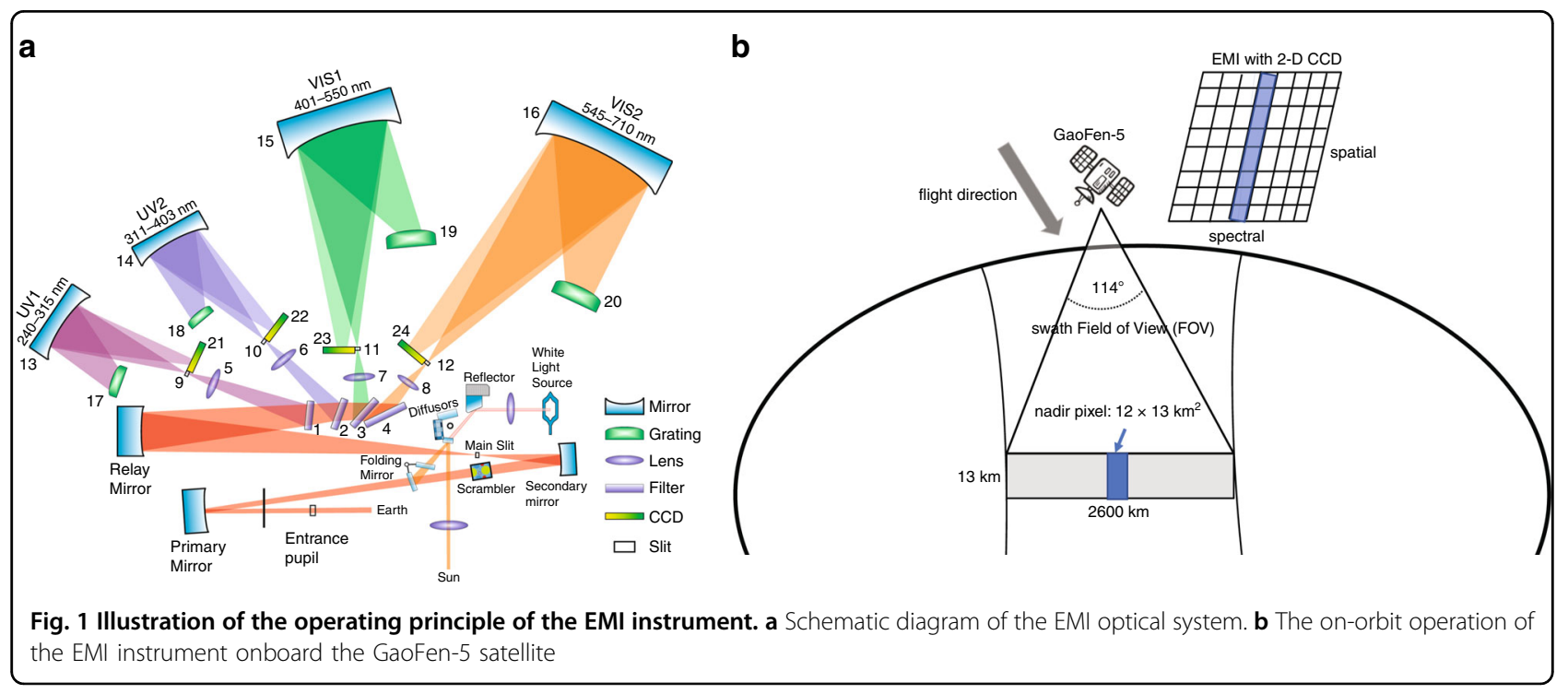



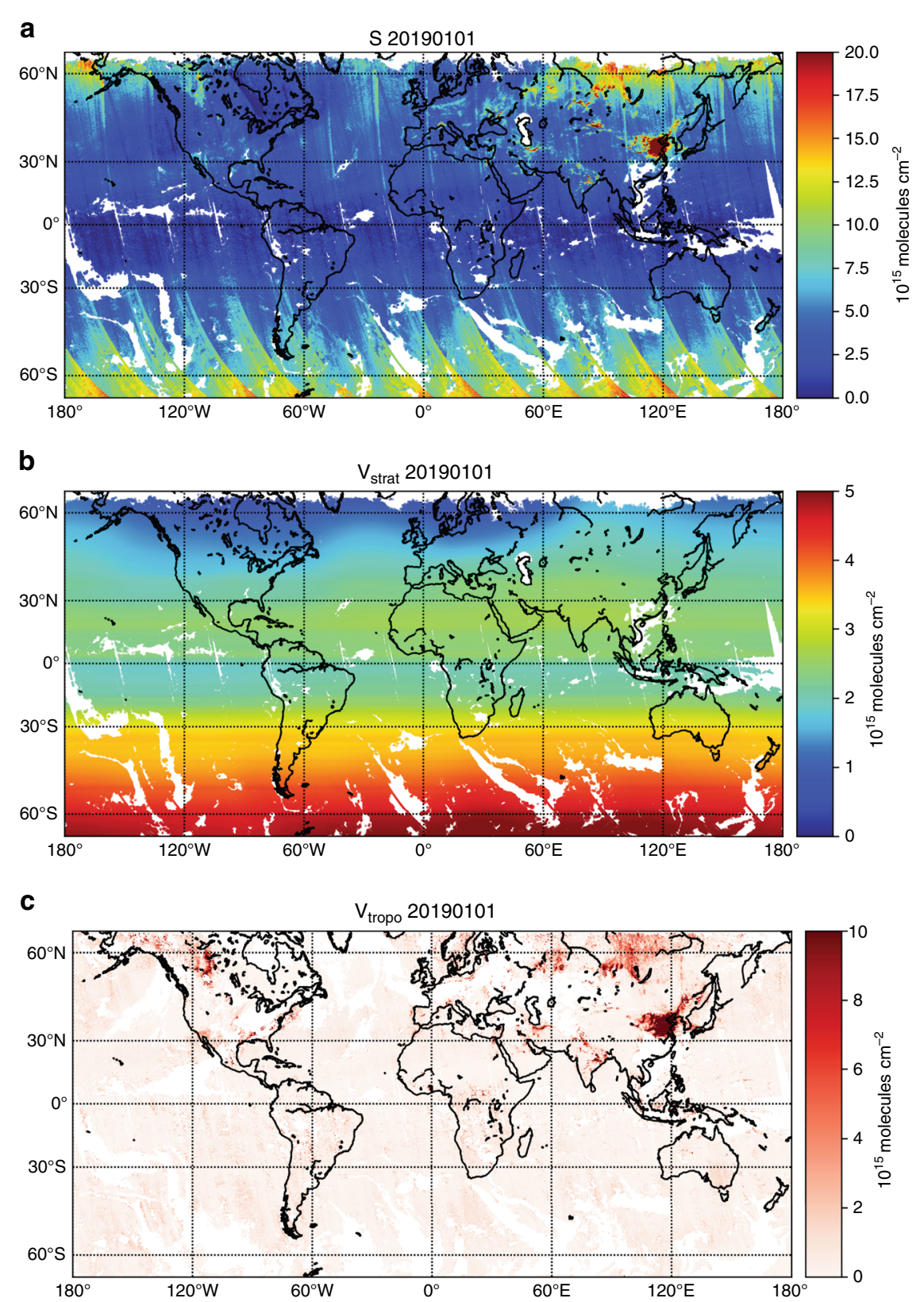

Fig. 2 An example of EMI NO${ }_{2}$ retrieval on 1 January 2019. The total SCDs $(S)$, stratospheric VCDs $\left(V_{\text {strat }}\right)$, and tropospheric VCDs $\left(V_{\text {tropo }}\right)$ retrieval of $\mathrm{NO}_{2}$ are shown in $\mathbf{a}, \mathbf{b}$, and $\mathbf{c}$, respectively. Note that satellite ground pixels affected by clouds are indicated in white

transfer model (RTM). The final tropospheric $\mathrm{NO}_{2} \mathrm{VCD}$ can be derived after subtracting the stratospheric contribution and AMF conversion:

$$
V_{\text {tropo }}=\frac{S-V_{\text {strat }} \times M_{\text {strat }}}{M_{\text {tropo }}}=\left(\frac{S}{M_{\text {strat }}}-V_{\text {strat }}\right) \times \frac{M_{\text {strat }}}{M_{\text {tropo }}}
$$

where $V_{\text {tropo }}$ and $V_{\text {strat }}$ denote tropospheric and stratospheric $V$, respectively. $M_{\text {tropo }}$ and $M_{\text {strat }}$ represent tropospheric and stratospheric $M$, respectively. Details of the stratospheric estimation and AMF calculation are provided in the "Materials and methods" section.

Figure 2 shows an example of EMI $\mathrm{NO}_{2}$ retrieval of $\mathrm{S}$, $V_{\text {strat }}$, and $V_{\text {tropo }}$ on 1 January 2019. Enhanced $\mathrm{NO}_{2}$ levels are observed in Eastern China, India, and the Middle East.

\section{Algorithm improvements}

A prototype EMI $\mathrm{NO}_{2}$ retrieval is developed before launch. The prototype algorithm is very similar to the 
Table $1 \mathrm{NO}_{2}$ retrieval settings used in the EMI and $\mathrm{OMI} \mathrm{NO}_{2}$ algorithms

\begin{tabular}{|c|c|c|}
\hline $\begin{array}{l}\text { Configurations and } \\
\text { parameters }\end{array}$ & OMI $\mathrm{NO}_{2}$ product (Boersma et al. ${ }^{17}$ ) & EMI $\mathrm{NO}_{2}$ product (in this study) \\
\hline \multicolumn{3}{|l|}{$\mathrm{NO}_{2}$ SCDs fitting } \\
\hline Wavelength range & $405-465 \mathrm{~nm}$ & $420-470 \mathrm{~nm}$ \\
\hline Radiometric calibration & Using calibrated (ir)radiance ${ }^{30}$ & Recalibrated the earth radiance measurements \\
\hline Reference spectrum & $\begin{array}{l}\text { Solar irradiance averaged between } 2005-2009 \\
\text { (ref. }{ }^{30} \text { ) }\end{array}$ & Daily earth radiance over the remote Pacific \\
\hline Instrument slit function & Preflight measured ${ }^{31}$ & Calibrated online by using solar atlas ${ }^{22}$, Gaussian shape assumed. \\
\hline \multicolumn{3}{|l|}{$\mathrm{NO}_{2}$ AMF calculations } \\
\hline $\begin{array}{l}\text { Radiative transfer } \\
\text { model (RTM) }\end{array}$ & Doubling-Adding KNMI (DAK) model ${ }^{17}$ & Vector Linearized Discrete Ordinate Radiative Transfer (VLIDORT) model ${ }^{14}$ \\
\hline Calculation method & Lookup table interpolation & Lookup table interpolation \\
\hline A priori $\mathrm{NO}_{2}$ profile & $\begin{array}{l}\text { The global chemistry Transport Model version } 5 \\
(\text { TM5 })^{32} \text { simulations at } 1 \times 1^{\circ}\end{array}$ & $\begin{array}{l}\text { The GEOS-Chem v10-01 at } 2 \times 2.5^{\circ} \text { for the global domain }{ }^{33} \text {, and WRF- } \\
\text { Chem v3.7 at } \sim 20 \mathrm{~km} \text { for the China domain }{ }^{34}\end{array}$ \\
\hline $\begin{array}{l}\text { Stratospheric-tropospheric } \\
\text { separation }\end{array}$ & Data assimilation ${ }^{17}$ & Reference sector method ${ }^{14}$ \\
\hline
\end{tabular}

operational OMI $\mathrm{NO}_{2}$ retrieval ${ }^{17}$. However, due to unexpected issues, i.e., low signal-to-noise ratio at the edges of the spectral channels, bad irradiance measurement due to a diffuser calibration issue, and spectral saturation issue, the $\mathrm{NO}_{2}$ retrieval setting must be further optimized to address these issues. A series of sensitivity tests, including cloud correction, fitting wavelength range, reference selection, and spectral precalibration, have been performed to optimize the settings for tropospheric $\mathrm{NO}_{2}$ VCD retrieval. Table 1 lists the updated retrieval settings of the EMI $\mathrm{NO}_{2}$ retrieval. Parameters used in the OMI QA4ECV NO retrieval $^{17}$ are also listed for reference.

The EMI $\mathrm{NO}_{2}$ fitting range is shifted slightly from 405-465 nm (OMI operational $\mathrm{NO}_{2}$ setting ${ }^{17}$ ) to $420-470 \mathrm{~nm}$ to avoid the lower signal-to-noise ratio region at the edges of the VIS1 channel ${ }^{12}$. Figure 3 illustrates an example of the retrieval of $\mathrm{NO}_{2} \mathrm{SCD}$, i.e., the $\mathrm{NO}_{2}$ amount integrated along the optical path in the atmosphere, by applying the DOAS fit to the EMI-measured spectrum.

The spectral saturation issue (i.e., the analogue photon signal reaches the maximum digital value of the CCD detector) is critical for EMI observations over bright clouds due to its high surface reflectance. Supplementary Figure 1 shows the global spatial pattern of the root mean square (RMS) of the spectral fitting residual, cloud radiance fraction from TROPOMI observations, and the true color image from the MODIS-Aqua instrument on 1 January 2019. The spatial pattern of the fitting residual RMS is correlated to the cloud pattern. Therefore, we filtered pixels with relatively large spectral fitting residuals, i.e., the RMS values $>0.004$.
The key calibration data measured during the on-ground calibration $^{12}$ seem unsuitable for EMI on-orbit measurements due to the degradation and stability of the instrument in the complex space environment (e.g., cosmic radiation exposure $^{18}$ and possible instrument changes since launch ${ }^{19}$ ). Therefore, we recalibrated the EMI earth radiance measurements by comparing the EMI radiance to TROPOMI measurements and RTM simulations. An advantage of DOAS is that it does not rely on precisely calibrated radiance and is less sensitive to the variability in radiometric calibration than other methods based on discrete radiance (e.g., SBUV and TOMS ozone retrieval algorithms ${ }^{20}$ ).

Figure 4 shows the comparisons of $\mathrm{NO}_{2} \mathrm{SCDs}$ for one orbit on 4 January 2019 retrieved using these spectral fitting scenarios: (a) current settings of the EMI $\mathrm{NO}_{2}$ retrieval listed in Table 1; (b) using the measured irradiance spectrum as a reference; and (c) same as in (a) but without spectral precalibration. Irradiance spectra measured by EMI are currently accounting for some calibration issues, and these issues are probably related to the interference of the space environment on the hemispheric reflectance of solar diffusers ${ }^{18}$. $\mathrm{NO}_{2}$ SCDs retrieved with irradiance as a reference show large biases and errors, particularly the central part of the measurement swath (Fig. 4b). Therefore, it is not optimal to use the direct sun irradiance spectra as a reference. To avoid the influence of abnormal irradiance spectra, we use cloud-free earth radiance measurements over the Pacific Ocean as a reference $^{21}$. Compared to using solar irradiance as a reference, using earth radiance as a reference greatly reduced the spectral noise in the fit residual (Fig. 4a, b), 


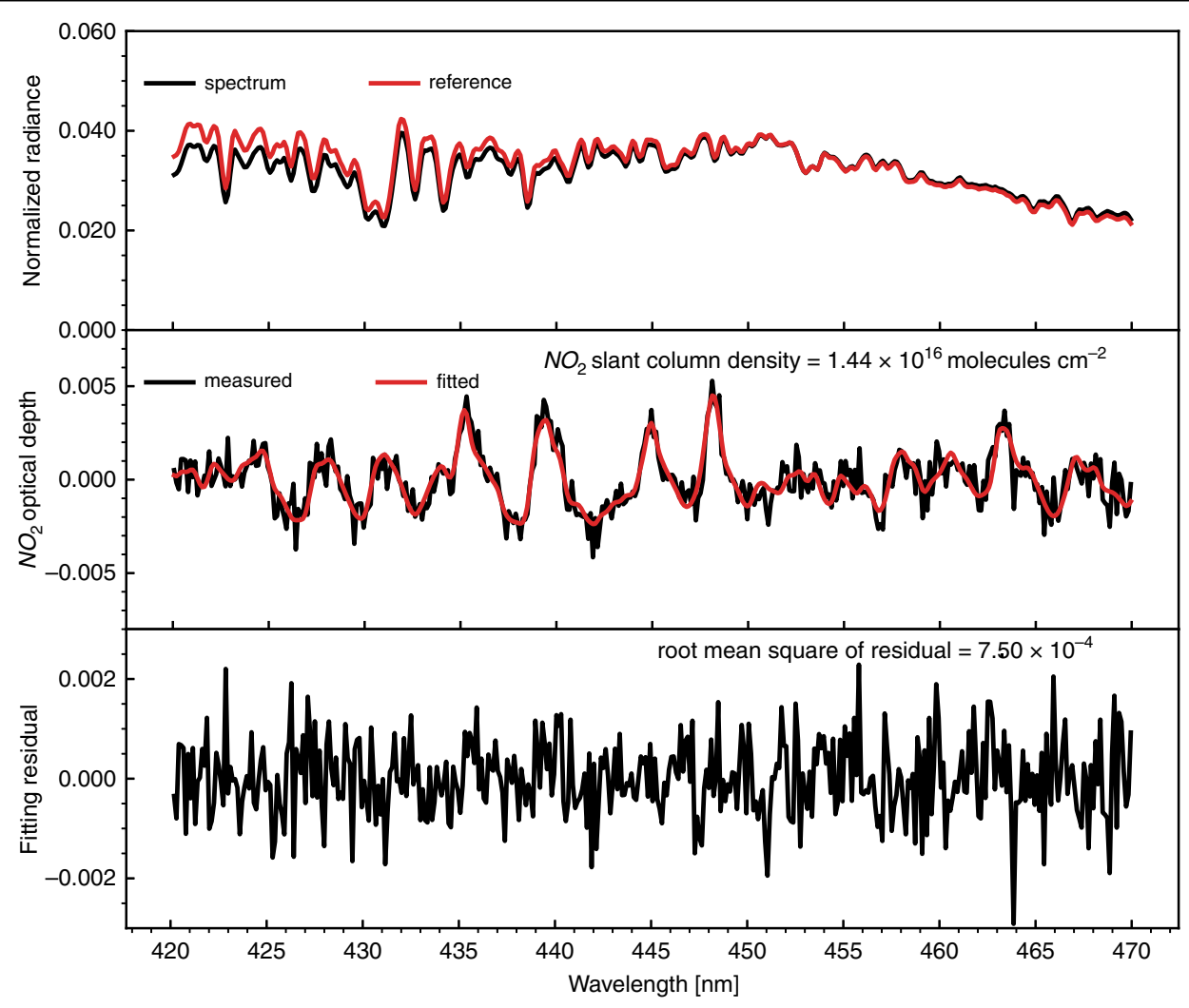

Fig. 3 An example of $\mathrm{NO}_{2}$ SCD retrieval from the EMI measurement spectra over Beijing on 15 May 2019. The top panel shows the fitted spectra and reference. The middle panel shows the measured and fitted $\mathrm{NO}_{2}$ optical depth. The spectral fit residual is shown in the bottom panel

which is likely related to the differences between spectra measured with the solar and earth-viewing modes ${ }^{21}$. The mean RMS of fitting residual by using earth radiance as a reference over cloud-free regions is $30 \%$ smaller than that with irradiance as a reference, as shown in Fig. 4a, b.

Although using radiance as a reference improved the spectral retrieval, the radiance reference also contains a $\mathrm{NO}_{2}$ absorption signal. Therefore, we must calculate the SCD offset to compensate for the residual $\mathrm{NO}_{2}$ signal in the reference spectrum. The SCD offset is calculated using the $\mathrm{NO}_{2}$ AMFs multiplied by the a priori $\mathrm{NO}_{2}$ profile taken from the GEOS-Chem model simulations (Supplementary Fig. 2). The $\mathrm{NO}_{2}$ simulation over clean remote regions is generally consistent with independent satellite observations, with a monthly mean bias of $<0.26 \times 10^{15}$ molecules $\mathrm{cm}^{-2}$ (Supplementary Fig. 3). Then, the SCD offset is added back to the $\mathrm{NO}_{2}$ SCDs. Note that the reference spectra are selected for each cross-track row to minimize the cross-track bias due to instrument artifacts. The systematic cross-track bias in EMI $\mathrm{NO}_{2}$ SCDs (the so-called "stripes", see Supplementary Fig. 4) is also observed for the OMI and TROPOMI products, and this bias can also be mitigated by using earth radiance as the reference spectrum ${ }^{21}$.
To account for the small variation in the spectral alignment due to the thermal variation in space $^{12}$, we calibrated the additional spectral shift or squeeze and instrument slit function through cross-correlation with a high-resolution solar spectrum atlas ${ }^{22}$ prior to the $\mathrm{NO}_{2}$ DOAS fitting. The precalibrated measurement spectra lead to an $\sim 30 \%$ smaller SCD fitting uncertainty than using initial calibration parameters (Fig. 4c), as well as a fit residual, and the SCD is nearly unchanged (within $\sim 3.3 \%$ ).

\section{Discussion}

The tropospheric $\mathrm{NO}_{2}$ VCDs retrieved from EMI spectra are first validated against the OMI QA4ECV NO products and the operational TROPOMI $\mathrm{NO}_{2}$ products ${ }^{23}$. EMI measurements are compared to the OMI and TROPOMI products due to their similar instrument characteristics, i.e., the push-broom design, spectral bands, and near-noon overpass time at $\sim 13: 30$. Note that the TROPOMI $\mathrm{NO}_{2}$ product generally followed the OMI QA4ECV $\mathrm{NO}_{2}$ retrieval algorithm, but TROPOMI has a higher signal-to-noise ratio and spatial resolution ${ }^{23}$. Figure 5 shows the monthly averaged $\mathrm{NO}_{2}$ VCDs measured by EMI, OMI, and TROPOMI in January 2019. EMI $\mathrm{NO}_{2}$ VCDs generally show similar spatial patterns and 


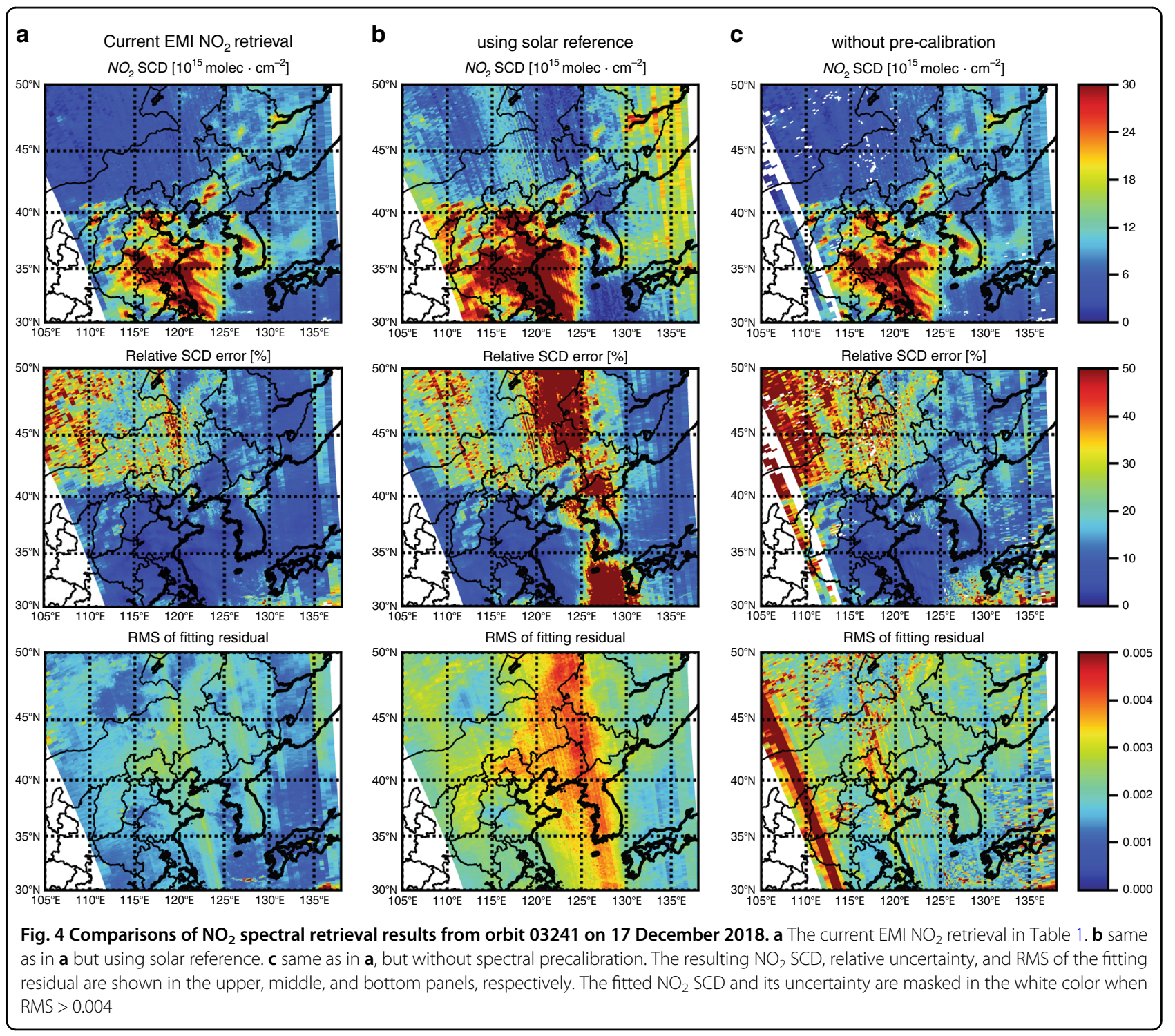

amplitudes of $\mathrm{NO}_{2}$ VCDs compared to OMI and TROPOMI, while finer-scale details of $\mathrm{NO}_{2}$ are captured by the satellite instrument with a higher spatial resolution. The EMI dataset overestimates $\mathrm{NO}_{2}$ VCDs by up to $50 \%$ over polluted regions, such as the North China Plain (NCP) and India (Fig. 5d) compared to the TROPOMI observations. The spatiotemporal correlations between EMI $\mathrm{NO}_{2}$ and TROPOMI $\mathrm{NO}_{2}$ were also evaluated. For data taken from January to August 2019, the correlation coefficient $(R)$ of daily mean $\mathrm{NO}_{2} \mathrm{VCD}$ time series over NCP between EMI and TROPOMI is 0.90, while the spatial correlation coefficient $(R)$ of mean $\mathrm{NO}_{2}$ VCDs over the NCP is 0.92 (Fig. 6). The remaining discrepancies between EMI and TROPOMI are mainly due to the $\mathrm{NO}_{2}$ vertical profile used in the tropospheric AMF calculation, while the spectral fitting method $(<3 \%)$ and stratospheric estimation method $(<10 \%)$ only show a minor contribution (Supplementary Fig. 5).

The EMI tropospheric $\mathrm{NO}_{2}$ VCDs are also compared to the ground-based $\mathrm{NO}_{2}$ measurements from the MultiAXis Differential Optical Absorption Spectroscopy (MAX-DOAS) instruments over northern China. A good agreement with a Pearson correlation coefficient $(R)$ of 0.82 is found between the two datasets during January-August 2019 (Fig. 7, Supplementary Fig. 6). However, EMI generally underestimates tropospheric $\mathrm{NO}_{2}$ VCDs by $30 \%$ compared to MAX-DOAS. The biases can be explained by the difference in spatial coverage between the ground-based and satellite observations ${ }^{24,25}$. In general, both satellite and ground-based validations of EMI $\mathrm{NO}_{2}$ measurements show good agreement with correlation coefficients $(R)$ of $0.8-0.9$, indicating that a 

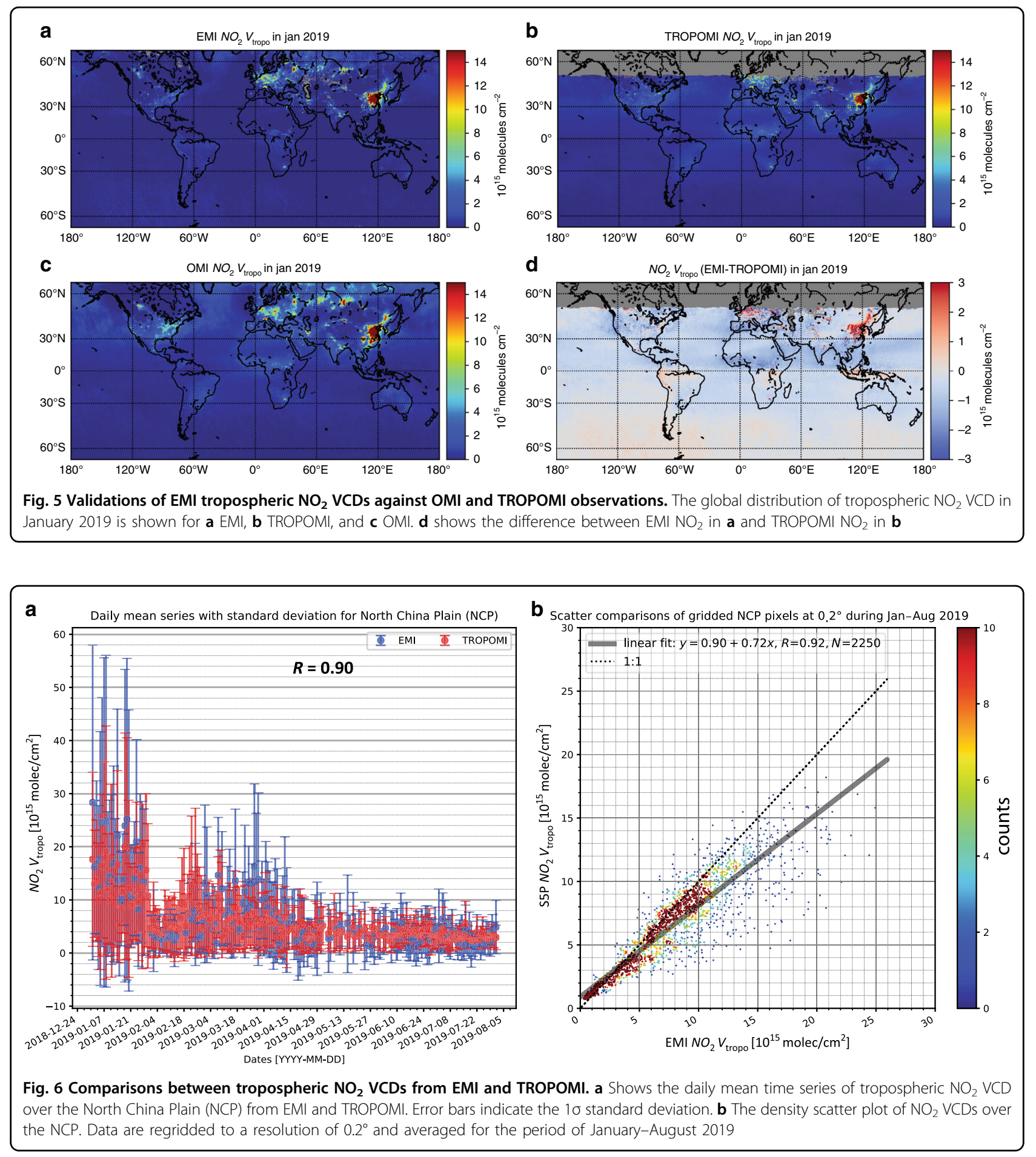

new EMI tropospheric $\mathrm{NO}_{2}$ retrieval provides reliable results for the investigation of air pollution distribution.

\section{Materials and methods}

The stratosphere-troposphere separation

The stratospheric contribution of $\mathrm{NO}_{2}$ must be subtracted from the total $\mathrm{NO}_{2}$ column to derive the tropospheric $\mathrm{NO}_{2}$ column. In the EMI $\mathrm{NO}_{2}$ retrieval, we used the STRatospheric Estimation Algorithm from Mainz ${ }^{14}$ to estimate the stratospheric contribution, which is based on the assumption that there is negligible contribution of tropospheric $\mathrm{NO}_{2}$ columns over the remote Pacific and cloudy pixels in the middle latitudes. The weighting factors based on cloud and polluted regions, 
MAX-DOAS validation of EMI $\mathrm{NO}_{2} V_{\text {tropo }}$ during Jan-Aug 2019

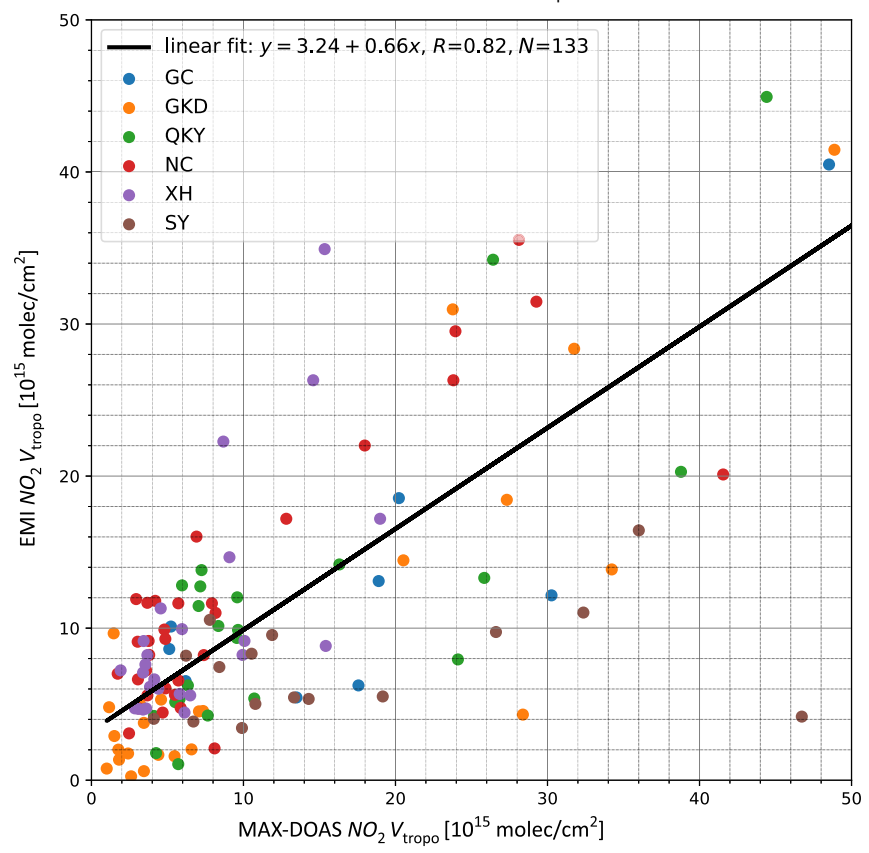

Fig. 7 Scatter plot of EMI tropospheric $\mathrm{NO}_{2}$ VCD against ground-based MAX-DOAS observations in northern China. Measurements from six different measurement sites are used in the comparison: the Gucheng site (GC, $\left.39.149^{\circ} \mathrm{N}, 115.734^{\circ} \mathrm{E}\right)$ in the Hebei Province, the Guokeda site (GKD, $\left.40.408^{\circ} \mathrm{N}, 116.675^{\circ} \mathrm{E}\right)$ in Beijing, the Qikeyuan (QKY, 39.9472 $\left.\mathrm{N}, 116.3206^{\circ} \mathrm{E}\right)$ site in Beijing, the Nancheng $\left(\mathrm{NC}, 39.781^{\circ} \mathrm{N}, 116.127^{\circ} \mathrm{E}\right)$ site in Beijing, the Xianghe site $\left(\mathrm{XH}, 39.750^{\circ} \mathrm{N}, 116.095^{\circ} \mathrm{E}\right)$ in the Hebei Province, and the Shengyang site $\left(\mathrm{SY}, 41.812^{\circ} \mathrm{N}, 123.401^{\circ} \mathrm{E}\right)$ in the Liaoning Province

which determines their impacts on the stratospheric estimate, are assigned to each satellite pixel. Subsequently, spatial smoothing based on weighted convolution is used to estimate the global stratospheric column.

\section{$\mathrm{NO}_{2}$ AMF calculations}

The EMI $\mathrm{NO}_{2}$ AMFs of each atmospheric layer (i.e., Box-AMFs) are calculated at $445 \mathrm{~nm}$ by the linearized pseudospherical vector model VLIDORT ${ }^{26}$ version 2.7. In addition to the solar and satellite-viewing geometries provided in the level 1 data, additional atmospheric and surface information are needed in the AMF calculations. Surface albedo at $442 \mathrm{~nm}$ is taken from the OMI minimum earth's surface Lambertian equivalent reflectance ${ }^{27}$ and interpolated to the EMI footprints. Considering the same local overpass time between EMI and TROPOMI, cloud top pressure and cloud fraction from TROPOMI ${ }^{28}$ are used for the calculations of EMI $\mathrm{NO}_{2}$ AMFs. A priori $\mathrm{NO}_{2}$ profiles are taken from the high-resolution $(\sim 20 \mathrm{~km})$ WRF-Chem simulations for the China domain and from GEOS-Chem simulations at the resolution of $2 \times 2.5^{\circ}$ for the global domain (Supplementary Fig. 7). The spatial resolution of the $\mathrm{NO}_{2}$ a priori profile is reportedly one of the dominant uncertainty sources during the $\mathrm{NO}_{2}$ AMF calculations $^{29}$. To expedite the calculation, these boxAMFs are precalculated and stored in the six-dimensional lookup table. Then, the box-AMF for each EMI observation can be derived by interpolating within the lookup table.

\section{Acknowledgements}

This research was supported by grants from the National Natural Science Foundation of China (nos. 41722501, 91544212, 51778596, and 41575021), the National Key Research and Development Program of China (nos. 2018YFC0213104, 2017YFC0210002, and 2016YFC0203302), the Strategic Priority Research Program of the Chinese Academy of Sciences (no. XDA23020301), the National Key Project for Causes and Control of Heavy Air Pollution (nos. DQGG0102 and DQGG0205), and the National High-Resolution Earth Observation Project of China (no. 05-Y30B01-9001-19/20-3).

\section{Author details}

${ }^{1}$ School of Earth and Space Sciences, University of Science and Technology of China, Hefei 230026, China. ${ }^{2}$ Department of Precision Machinery and Precision Instrumentation, University of Science and Technology of China, Hefei 230026, China. ${ }^{3}$ Key Laboratory of Environmental Optics and Technology, Anhui Institute of Optics and Fine Mechanics, Chinese Academy of Sciences, Hefei 230031, China. ${ }^{4}$ Center for Excellence in Regional Atmospheric Environment, Institute of Urban Environment, Chinese Academy of Sciences, Xiamen 361021, China. ${ }^{5}$ Key Laboratory of Precision Scientific Instrumentation of Anhui Higher Education Institutes, University of Science and Technology of China, Hefei 230026, China. ${ }^{6}$ Remote Sensing Technology Institute (IMF), German Aerospace Center (DLR), Oberpfaffenhofen, Germany

\section{Author contributions}

C.Z. performed the data analysis and wrote the manuscript. C.L. supervised this research and conceived the idea. K.L.C. contributed to the data interpretation and manuscript revisions. H.L., B.L., C.X., and W.T. processed the MAX-DOAS data. H.Z., F.S., and J.L. built the EMI instrument. C.Z. prepared the paper with inputs from all co-authors. 


\section{Data availability}

The EMI level 1 and $\mathrm{NO}_{2}$ datasets are available from Cheng Liu (chliu81@ustc. edu.cn) upon reasonable request. The OMI QA4ECV NO 2 and TROPOMI $\mathrm{NO}_{2}$ datasets are available from http://www.temis.nl/airpollution/no2.html.

\section{Conflict of interest}

The authors declare that they have no conflict of interest.

Supplementary information is available for this paper at https://doi.org/ 10.1038/s41377-020-0306-z.

Received: 24 December 2019 Revised: 23 March 2020 Accepted: 30 March 2020

Published online: 20 April 2020

\section{References}

1. Zhang, C. X. et al. Preflight evaluation of the performance of the chinese environmental trace gas monitoring instrument (EMI) by spectral analyses of nitrogen dioxide. IEEE Trans. Geosci. Remote Sens. 56, 3323-3332 (2018).

2. Levelt, P. F. et al. The ozone monitoring instrument. IEEE Trans. Geosci. Remote Sens. 44, 1093-1101 (2006).

3. Veefkind, J. P. et al. TROPOMI on the ESA Sentinel-5 Precursor: a GMES mission for global observations of the atmospheric composition for climate, air quality and ozone layer applications. Remote Sens. Environ. 120, 70-83 (2012).

4. Atkinson, R. Atmospheric chemistry of VOCs and $\mathrm{NO}_{x}$. Atmos. Environ. 34, 2063-2101 (2000).

5. Liu, F. et al. Recent reduction in $\mathrm{NO}_{x}$ emissions over China: synthesis of satellite observations and emission inventories. Environ. Res. Lett. 11, 114002 (2016).

6. Crippa, M. et al. Gridded emissions of air pollutants for the period 1970-2012 within EDGAR v4.3.2. Earth Syst. Sci. Data 10, 1987-2013 (2018).

7. An, Z. S. et al. Severe haze in northern China: a synergy of anthropogenic emissions and atmospheric processes. Proc. Natl Acad. Sci. USA 116, 8657-8666 (2019).

8. Gao, M. et al. Estimates of health impacts and radiative forcing in winter haze in eastern china through constraints of surface $\mathrm{PM}_{2.5}$ predictions. Environ. Sci. Technol. 51, 2178-2185 (2017)

9. Liu, F. et al. $\mathrm{NO}_{x}$ emission trends over Chinese cities estimated from $\mathrm{OMI}$ observations during 2005 to 2015. Atmos. Chem. Phys. 17, 9261-9275 (2017)

10. Zhang, C.X. et al. Satellite UV-Vis spectroscopy: implications for air quality trends and their driving forces in China during 2005-2017. Light. Sci. Appl. 8, 100 (2019).

11. Liu, X. L. et al. Assimilation of satellite $\mathrm{NO}_{2}$ observations at high spatial resolution using OSSEs. Atmos. Chem. Phys. 17, 7067-7081 (2017)

12. Zhao, M. J. et al. Preflight calibration of the Chinese Environmental trace gases monitoring instrument (EMI). Atmos. Meas. Tech. 11, 5403-5419 (2018).

13. Platt, U. \& Stutz, J. Differential Optical Absorption Spectroscopy, pp 135-174 (Springer, Berlin, Heidelberg, 2008).

14. Beirle, S. et al. The STRatospheric Estimation Algorithm from Mainz (STREAM): estimating stratospheric $\mathrm{NO}_{2}$ from nadir-viewing satellites by weighted convolution. Atmos. Meas. Tech. 9, 2753-2779 (2016).
15. Valks, P. et al. Operational total and tropospheric $\mathrm{NO}_{2}$ column retrieval for GOME-2. Atmos. Meas. Tech. 4, 1491-1514 (2011).

16. Palmer, P. I. et al. Air mass factor formulation for spectroscopic measurements from satellites: application to formaldehyde retrievals from the global ozone monitoring experiment. J. Geophys. Res. 106, 14539-14550 (2001).

17. Boersma, K. F. et al. Improving algorithms and uncertainty estimates for satellite $\mathrm{NO}_{2}$ retrievals: results from the quality assurance for the essential climate variables (QA4ECV) project. Atmos. Meas. Tech. 11, 6651-6678 (2018).

18. Zhao, M. J. et al. Effect of AO/UV/RD exposure on spaceborne diffusers: a comparative experiment. Appl. Opt. 54, 9157-9166 (2015).

19. Schenkeveld, V. M. E. et al. In-flight performance of the ozone monitoring instrument. Atmos. Meas. Tech. 10, 1957-1986 (2017).

20. Heath, D. F. et al. The solar backscatter ultraviolet and total ozone mapping spectrometer (SBUV/TOMS) for Nimbus G. Optical Eng. 14, 144323 (1975).

21. Anand, J. S., Monks, P. S. \& Leigh, R. J. An improved retrieval of tropospheric $\mathrm{NO}_{2}$ from space over polluted regions using an Earth radiance reference. Atmos. Meas. Tech. 8, 1519-1535 (2015).

22. Chance, K. \& Kurucz, R. L. An improved high-resolution solar reference spectrum for earth's atmosphere measurements in the ultraviolet, visible, and near infrared. J. Quant. Spectrosc. Radiat. Transf. 111, 1289-1295 (2010).

23. Griffin, D. et al. High-resolution mapping of nitrogen dioxide with TROPOMl: first results and validation over the canadian oil sands. Geophys. Res. Lett. 46 1049-1060 (2019)

24. Chan, K. L. et al. Observations of tropospheric aerosols and $\mathrm{NO}_{2}$ in Hong Kong over 5 years using ground based MAX-DOAS. Sci. Total Environ. 619-620, 1545-1556 (2018)

25. Chan, K. L. et al. MAX-DOAS measurements of tropospheric $\mathrm{NO}_{2}$ and $\mathrm{HCHO}$ in Nanjing and a comparison to ozone monitoring instrument observations. Atmos. Chem. Phys. 19, 10051-10071 (2019).

26. Spurr, R. J. D. VLIDORT: a linearized pseudo-spherical vector discrete ordinate radiative transfer code for forward model and retrieval studies in multilayer multiple scattering media. J. Quant. Spectrosc. Radiat. Transf. 102, 316-342 (2006).

27. Kleipool, Q. L. et al. Earth surface reflectance climatology from 3 years of OMI data. J. Geophys. Res. 113, D18308 (2008).

28. Loyola, D. G. et al. The operational cloud retrieval algorithms from TROPOMl on board Sentinel-5 Precursor. Atmos. Meas. Tech. 11, 409-427 (2018).

29. Kuhlmann, $\mathrm{G}$. et al. Development of a custom $\mathrm{OMI} \mathrm{NO}_{2}$ data product for evaluating biases in a regional chemistry transport model. Atmos. Chem. Phys. 15, 5627-5644 (2015)

30. van den Oord, G. H. J. et al. OMl level 0 to $1 \mathrm{~b}$ processing and operational aspects. IEEE Trans. Geosci. Remote Sens. 44, 1380-1397 (2006).

31. Dirksen, R. et al. Prelaunch characterization of the Ozone Monitoring Instrument transfer function in the spectral domain. Appl. Opt. 45, 3972-3981 (2006).

32. Williams, J. E. et al. The high-resolution version of TM5-MP for optimized satellite retrievals: description and validation. Geosci. Model Dev. 10, 721-750 (2017).

33. Wang, S. W. et al. Growth in $\mathrm{NO}_{x}$ emissions from power plants in China: bottom-up estimates and satellite observations. Atmos. Chem. Phys. 12, 4429-4447 (2012).

34. Su, W. J. et al. Characterization of ozone in the lower troposphere during the 2016 G20 conference in Hangzhou. Sci. Rep. 7, 17368 (2017). 